\title{
puente Volta
}

PETER ADAMSON SCOTT y GILBERT ROBERTS, ingoniero

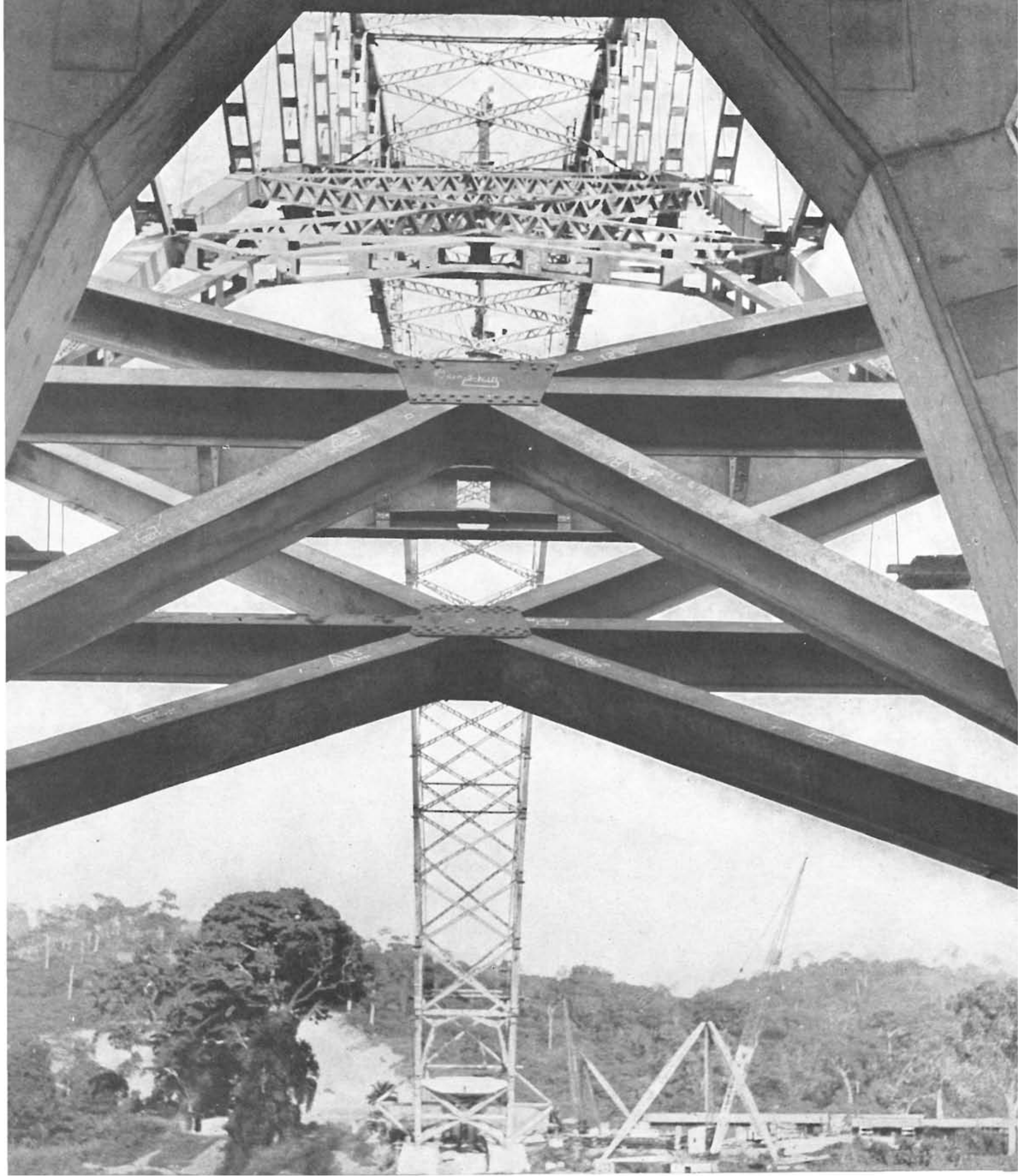


INSTITUTO TECNICO DE LA CONSTRUCCION Y DEL CEMENTO

La creciente revaloración nacional y aumento de precio del cacao han dado una nueva potencialidad al antiguo estado de Costa de Oro, hoy conocido con el nombre de Ghana, cuya fusión con sus vecinos de Togoland constituye actualmente una nacionalidad en vías de prosperidad.

La zona de Togoland se halla separada del resto de estos territorios por el caudaloso río Volta, creando una barrera que oponía serias dificultades para el paso de las mercancías o productos naturales que, para su exportación, se dirigían a los puertos de embarque después de cruzar el río por transbordadores.

Para dar una solución definitiva a esta forma de salvar el río por medio de embarcaciones, se pensó en la construcción de un puente estable y permanente que evitase los retrasos y las incomodidades ocasionados por todo paso fluvial de esta naturaleza.

Un estudio geotopográfico de los lugares más apropiados para la ubicación de la obra llevó a la conclusión de que, tenida cuenta de todas las circunstancias presentes actuales y las que en el futuro pudieran derivarse, el lugar más apropiado para salvar el río con un puente se hallaba en las proximidades de Adomi, a unos $100 \mathrm{~km}$ al noreste de Accra.

En este paraje, el río se encauza formando un estrecho paso cuyas laderas se prestan bien para apoyar sobre roca firme los estribos.

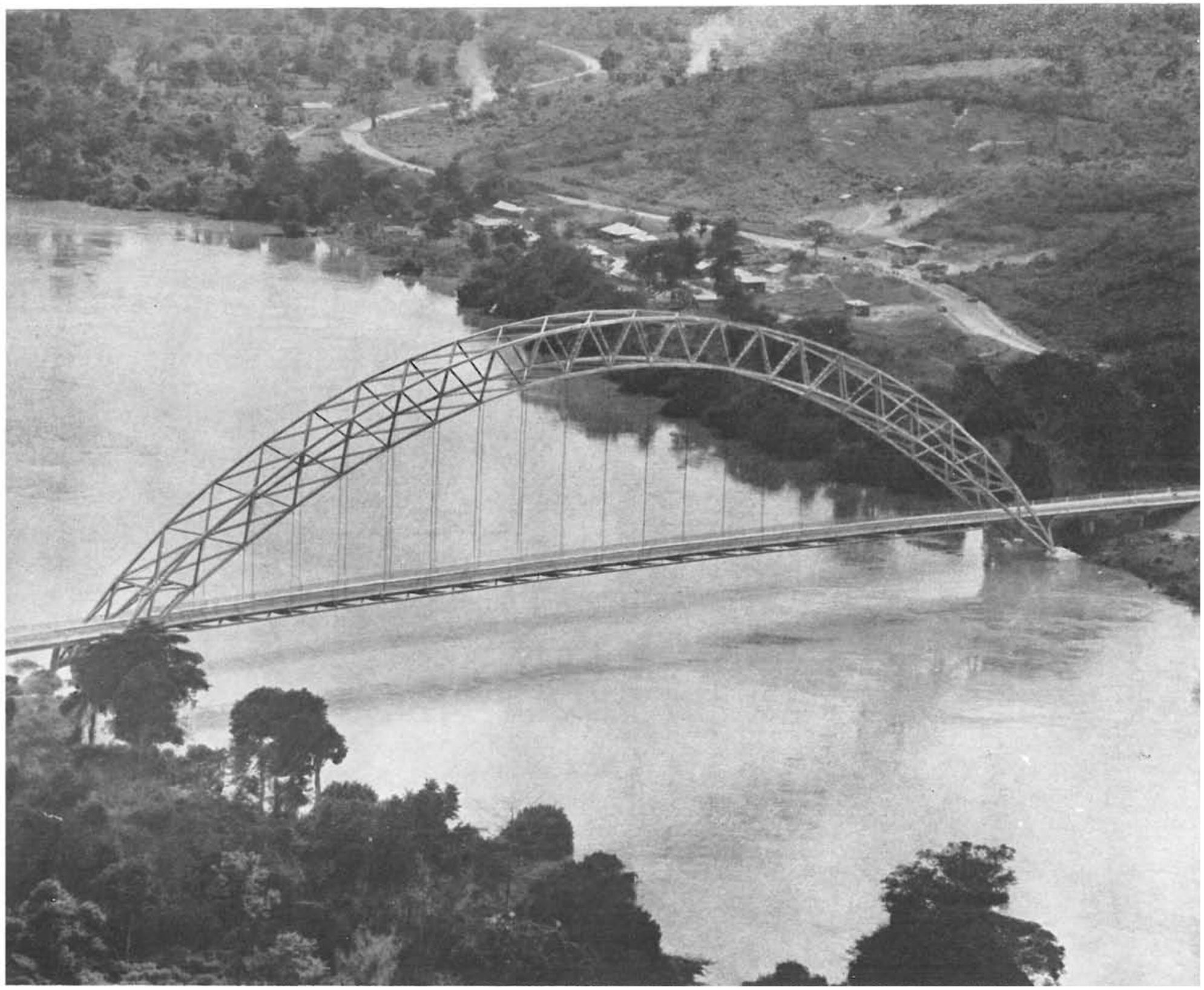




\section{planta y alzado}
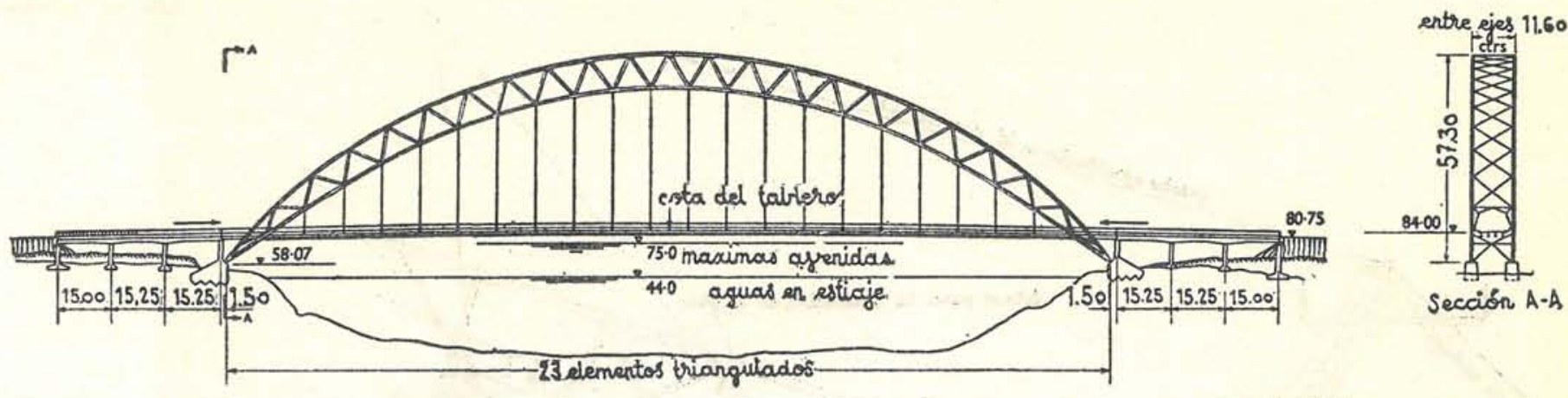

Sale: 1 in. $-200 \mathrm{ft}$

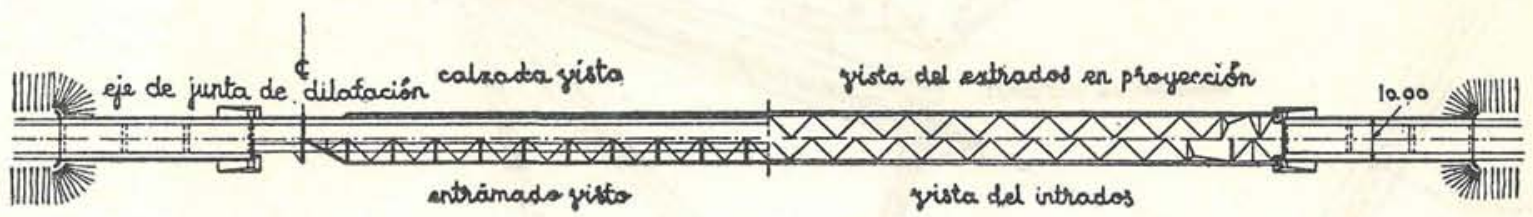

El lugar elegido lleva consigo la construcción de unos ocho kilómetros de nueva carretera de acceso al puente en una y otra ladera del cauce del río. Como el río es caudaloso y propenso a grandes avenidas, el puente tenía que presentar un desagüe suficiente para hacer frente a esta eventualidad. Esta última condición, exigió levantar el tablero y tramos de accesos para ampliar la sección disponible que forma el perímetro mojado variable según el caudal.

El puente está constituído por seis tramos de acceso, tres en cada estribo, de hormigón armado, de $15 \mathrm{~m}$ de luz aproximadamente, y un tramo central. Este tramo central es el que absorbe y domina la importancia de la obra; tiene $256 \mathrm{~m}$ de luz, y está formado por una estructura metálica, en arco parabólico, triangulada, de altura máxima en la clave $(9,75$ metros), que va disminuyendo hasta los estribos, donde se unen las dos cabezas de las dos celosías trianguladas formando arco, espaciados a $12,20 \mathrm{~m}$, constituyendo cajón y formando una articulación en el estribo. Las cuatro cabezas de las dos grandes cerchas o arcos paralelos, arriostrados entre ellos por dos triangulaciones transversales que siguen la curvatura del arco, están constituídas por otras tantas vigas cajón, cuyas partes internas permiten el acceso personal reducido, pero suficiente para su inspección.

Así, pues, el tramo central es de dos articulaciones y sirve de apoyo para suspender el tablero por medio de péndolas, constituídas por cables metálicos espaciados a $10,60 \mathrm{~m}$. La flecha de la parábola del intradós respecto a un plano que pasa por las articulaciones es de, aproximadamente, 50 metros.

El entramado que sirve de apoyo a la calzada, de 6,70 $\mathrm{m}$ de anchura, de hormigón, y una capa asfáltica, de $2,5 \mathrm{~cm}$ de espesor, como superficie de rodadura, se han formado con dos vigas paralelas sobre las que se apoyan otras transversales, de forma lenticular en sección, cuyo espaciamiento es coincidente con el de las péndolas.

Disposición de los pernos de unión en. tre elementos de las cabezas de sección rectangular hueca o cajón.
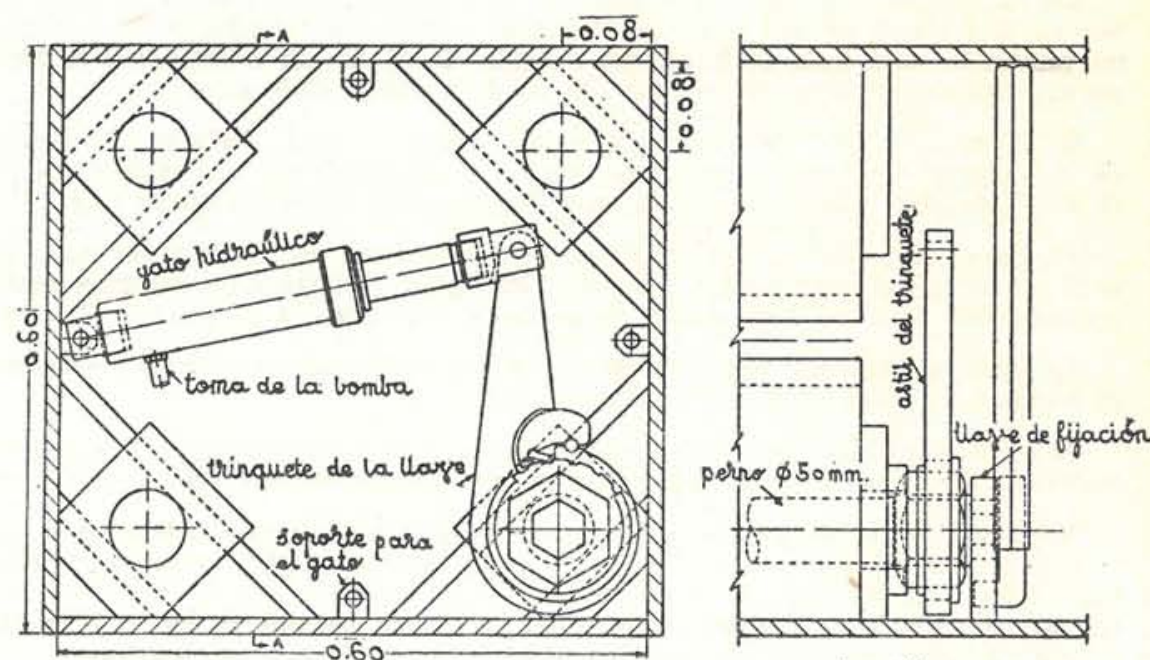

Sección A-A 


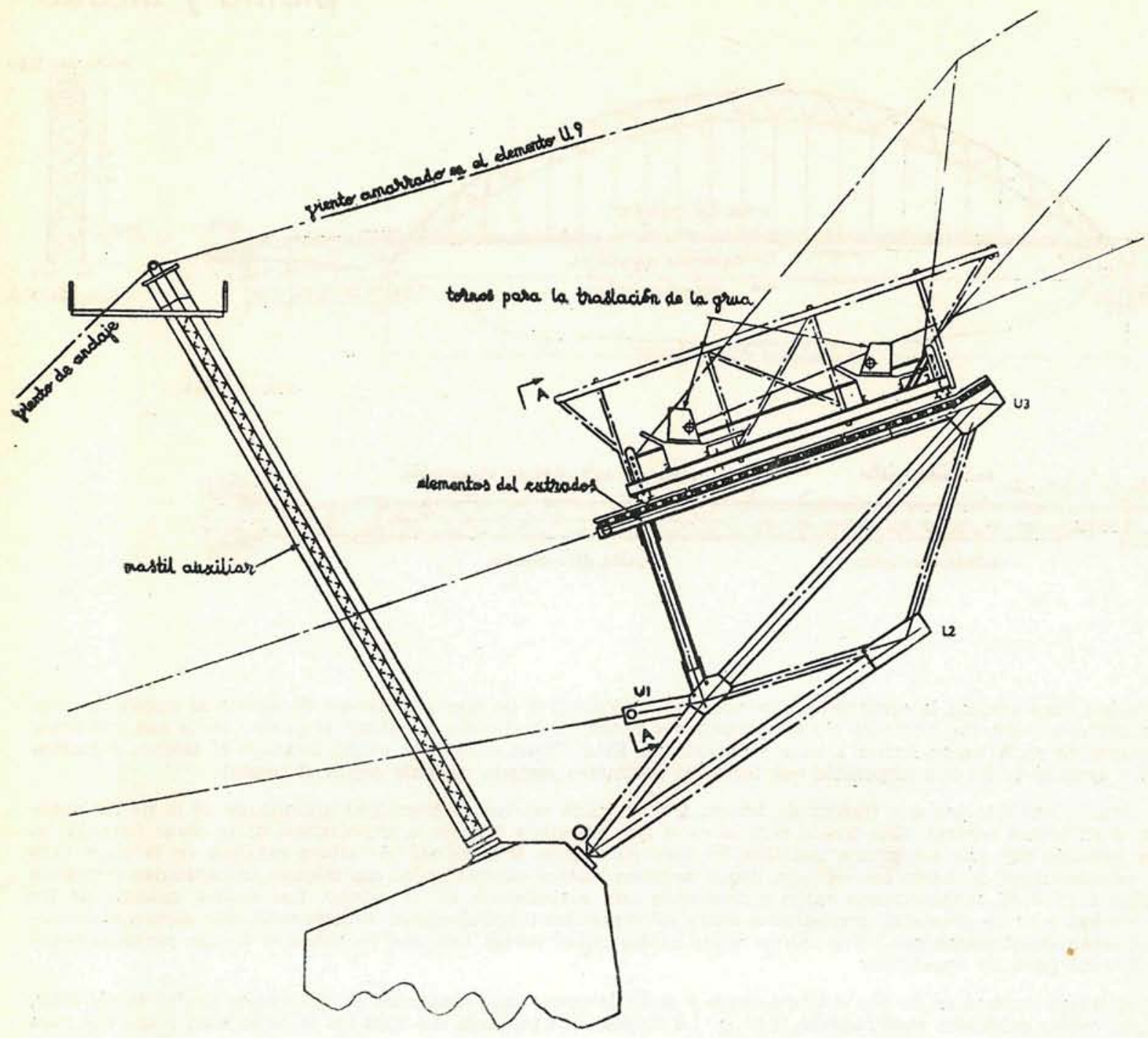

En la zona ínferior del entramado así constituído se han montado los elementos de arriostramiento, formando rombos cuyos vértices se han unido rígidamente a las vigas longitudinales y transversales. Sobre las vigas transversales se ha construído una losa, de hormigón armado, de $15 \mathrm{~cm}$ de espesor, que se levanta y vuela en sus extremidades laterales para constituir los dos andenes de $1,50 \mathrm{~m}$ de anchura cada uno.

Salvo la parte reservada al montaje del puente en obra, todos sus elementos se han solidarizado $\mathrm{y}$ unido por medio de la soldadura eléctrica, pero, con objeto de disminuir en la medida de lo posible las operaciones de conservación, todo el acero, cie alta resistencia, se ha embadurnado con una solución de cinc.

Al proyectar la estructura se adoptó una velocidad de $130 \mathrm{~km}$ por hora para el viento a $12 \mathrm{~m}$ de altura sobre el agua; $\pm 22^{\circ} \mathrm{C}$ de temperatura variable; hormigón trabajando a flexión a razón de $78 \mathrm{~kg} / \mathrm{cm}^{2} ; 1.898 \mathrm{~kg} / \mathrm{cm}^{2} \mathrm{para}$ el acero en redondos; $1.400 \mathrm{~kg} / \mathrm{cm}^{2}$ para el acero dulce, y 12 para la relación modular en el hormigón.

La estética debía ser causa de estudio, y con objeto de conocer los efectos de las grandes avenidas en el río se estudió el régimen de éstas en modelo reducido.

El empuje previsto en estribos se calculó en unas 2.000 toneladas, lo que motivó la construcción de grandes blocues de hormigón en masa en su núcleo y ligeramente armado en lą zona superficial para los estribos.

Adoptada la forma general de un arco parabólico de doble articulación, así como su montaje volando sobre el río, utilizando ung zona auxiliar de moniaje en la extremidad dol voladizo, se estudiaron los anclajes que debian preverse para retener el voladiso en posición durante in construceión. Se procuró, por todos los medios, lograr una estructura ligera y agradable a la vista, conservando su forma parabólica en el intradós y de parábola mixta para el extradós, cuya separación decrecía, logarítmicamente, desde ia ciave a estribos, donde se unen las dos parábolas de las cabezas de las cerchas o arcos paralelos. 

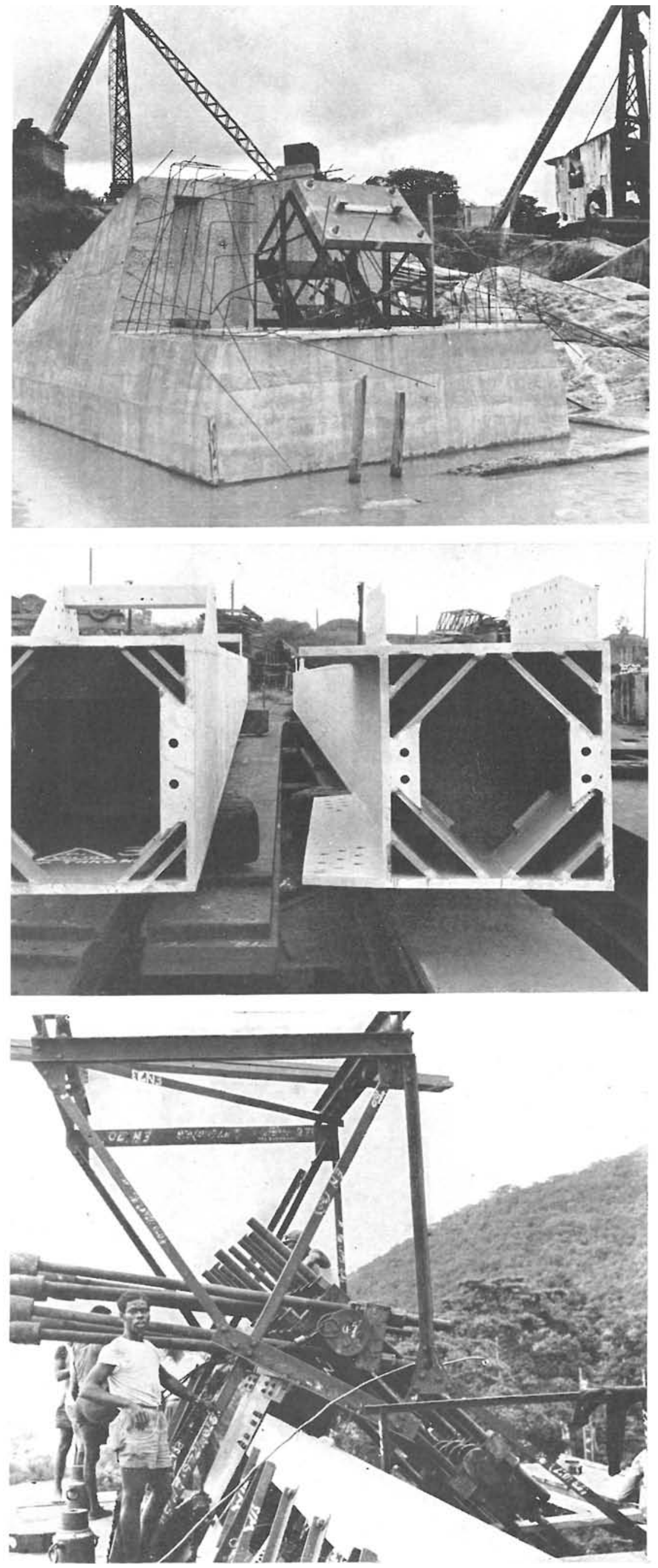

Placa de la articulación en el estribo antes de hormigonar.

Elementos de las cabezas inferiores $y$ superiores.

Parte superior del mástil provisional.

Al especular con la variable flecha se analizaron varias alturas $\mathrm{y}$ aligeramientos de peso, llegando a la conclusión que la relación $1 / 5$ entre flecha y luz era la más aceptable.

Se estudió, con especial cuidado, la distribución de esfuerzos en los arcos, para que las tensiones fueran similares en las dos cabezas de los arcos. En la parte central o clave se previó una unión curva formando una especie de articulación, en la que una de sus caras curvas, la de superficie cóncava, proyectase dos tetones salientes que se alojarían en huecos practicados en la cara opuesta de contacto o junta. Esta disposición permitiría una unión solidaria.

Una característica particular del montaje de los elementos estructurales es la supresión de platabandas, pernos y roblones trabajando a cizalla o esfuerzo cortante. Así, por ejemplo, la unión de las distintas partes formando cajón en que se han subdividido las cabezas de los arcos, se han unido con unos pernos que trabajan simplemente a tracción. En el interior de estos cajones o trozos de cabeza y en las zonas de unión con los contiguos se soldaron cuatro cartelas, provistas de los correspondientes taladros para dar paso a los pernos longitudinales que se utilizarían en la fijación de la unión entre trozos de cada una de las cabezas. Esta disposición planteó el problema de la tensión que debía darse a cada perno en función del grado de enroscado. Esta operación, de no fácil determinación, se salvó en la obra preparando un dispositivo especial de enroscado mecánico para dar la tensión debida a los pernos de acuerdo con la presión en el gato hidráulico que se utilizaba para apretar la tuerca.

Otro de los cuidados prodigados en el análisis estructural consistió en prever las deformaciones, propias e inherentes al método constructivo, que suelen tener por resultado el bajar la altura teórica en la clave $\mathrm{y}$, por consiguiente, la falta de encaje en la unión correspondiente a la clave. Todas las uniones debían trabajar a compresión, y la de la clave permitiría comportarse como si se tratase de una articulación.

La parte metálica de la estructura, cuyas cabezas o cajones se han formado con chapa de $9 \mathrm{~mm}$ de espesor, se ha preparado en el taller. 


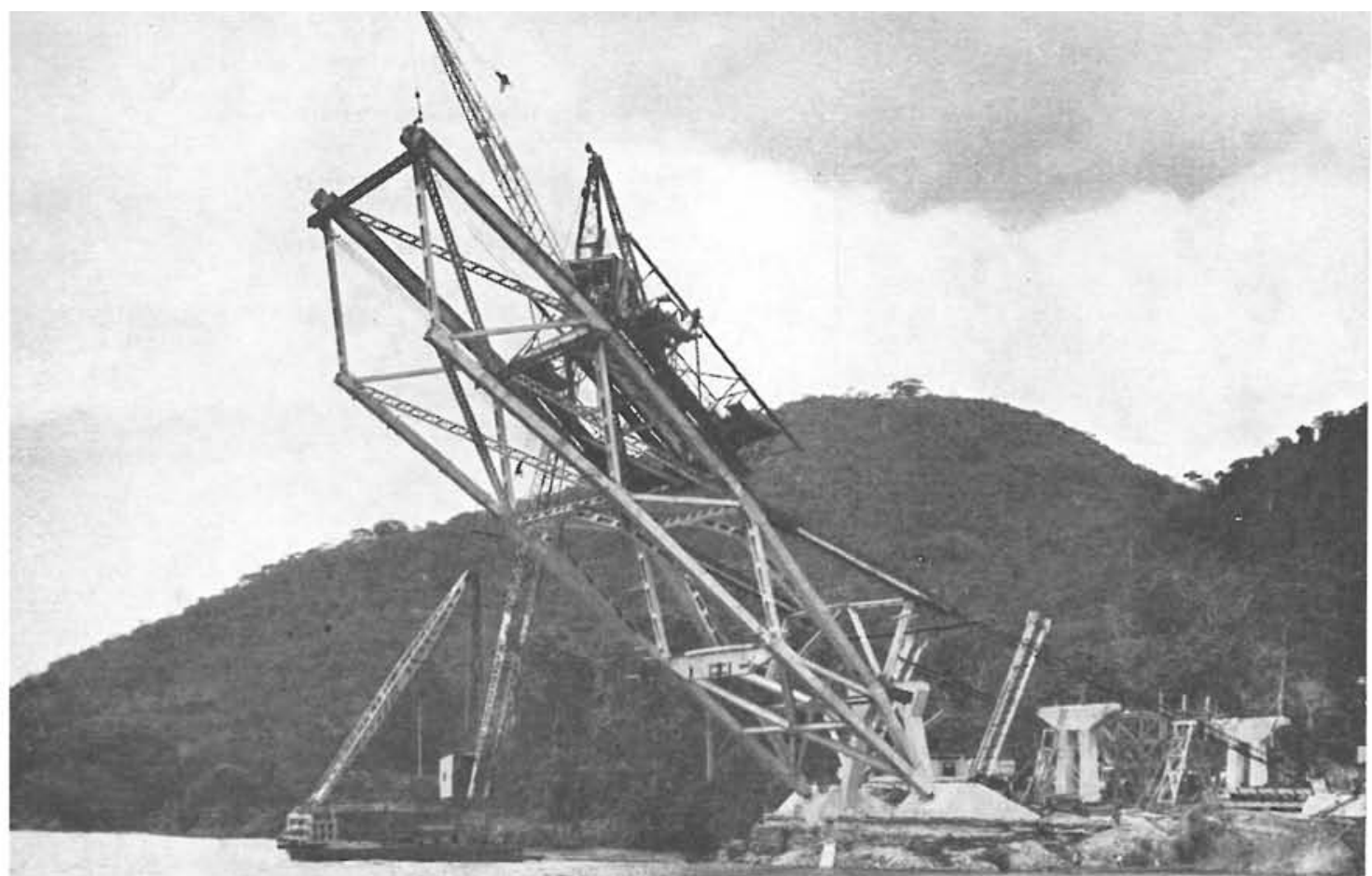

La grúa de montaje en su posición inicial.

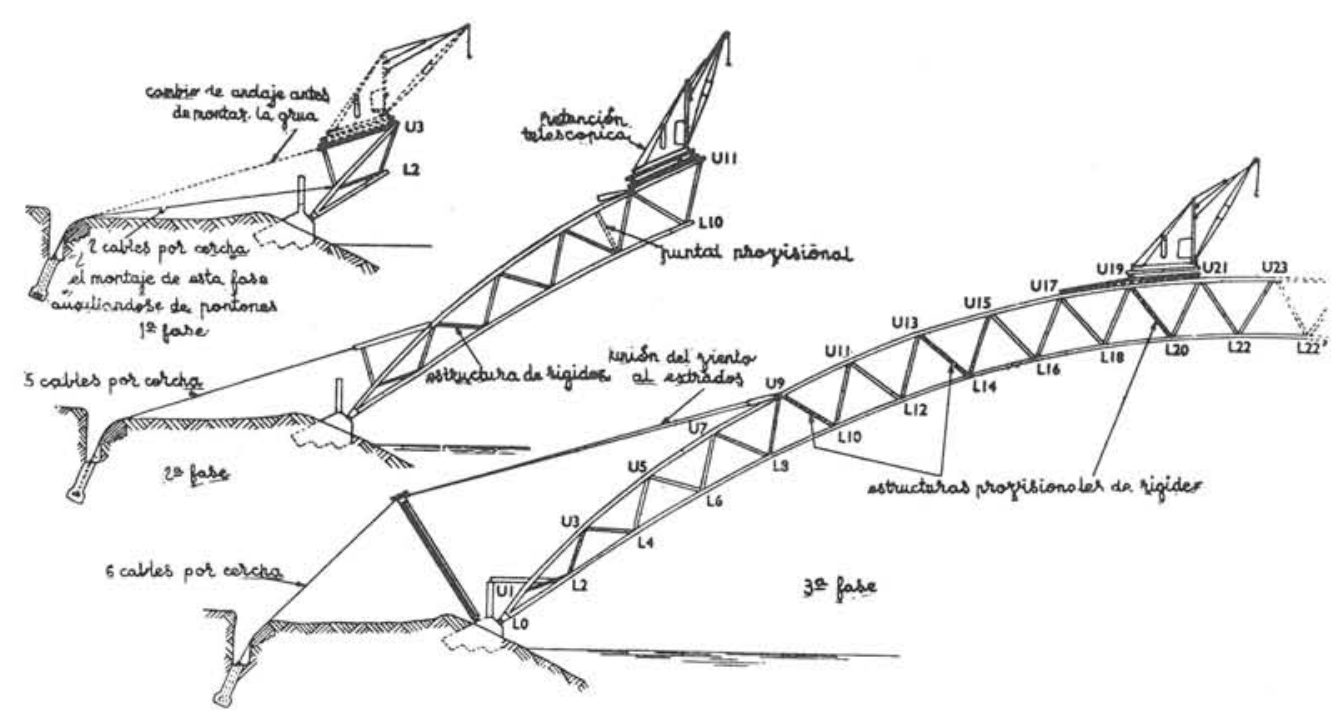

Las tres fases de montaje.

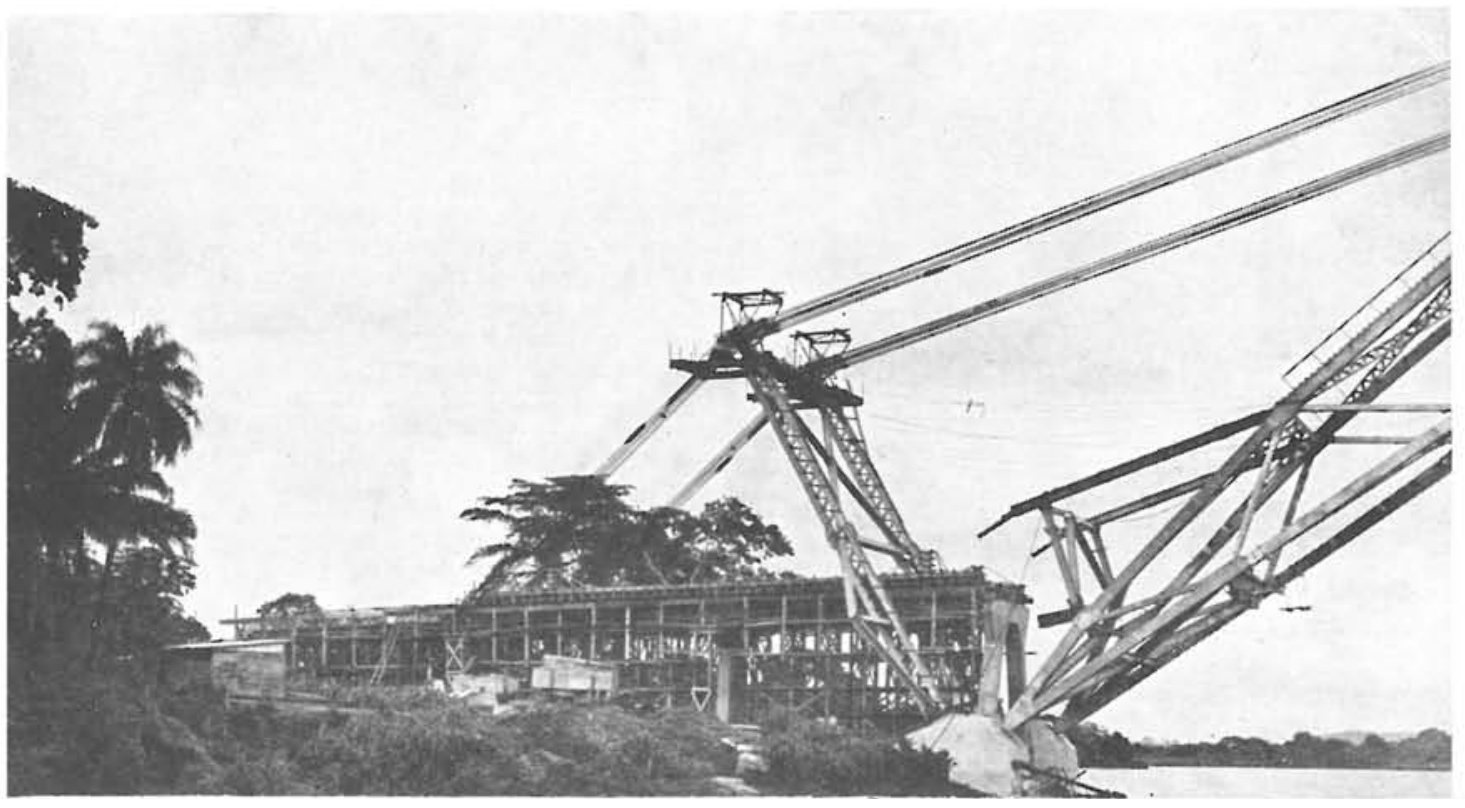

Mástil auxiliar y vientos anclados en tierra. 

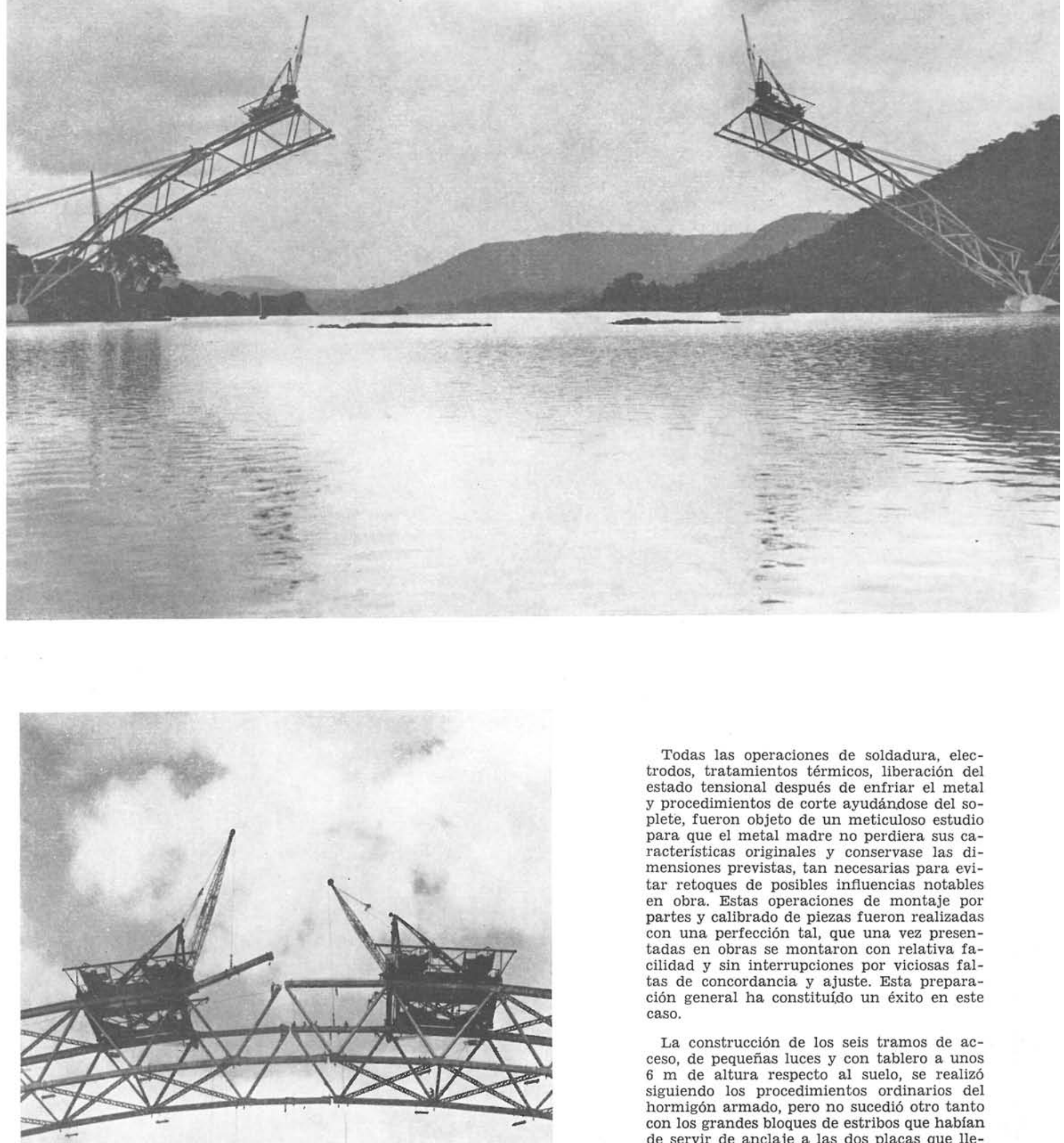

Todas las operaciones de soldadura, electrodos, tratamientos térmícos, liberación del estado tensional después de enfriar el metal y procedimientos de corte ayudándose del soplete, fueron objeto de un meticuloso estudio para que el metal madre no perdiera sus características originales y conservase las dimensiones previstas, tan necesarias para evitar retoques de posibles influencias notables en obra. Estas operaciones de montaje por partes y calibrado de piezas fueron realizadas con una perfección tal, que una vez presentadas en obras se montaron con relativa facilidad y sin interrupciones por viciosas faltas de concordancia y ajuste. Esta preparacíon general ha constituído un éxito en este caso.

La construcción de los seis tramos de acceso, de pequeñas luces y con tablero a unos $6 \mathrm{~m}$ de altura respecto al suelo, se realizó siguiendo los procedimientos ordinarios del hormigón armado, pero no sucedió otro tanto con los grandes bloques de estribos que habían de servir de anclaje a las dos placas que llevan los órganos de las articulaciones en cada bloque.

En los reconocimientos previos del terreno se habían perforado grandes bloques sueltos de roca que parecían ser de un banco "in situ", cosa que luego se demostró no ser cierta. 

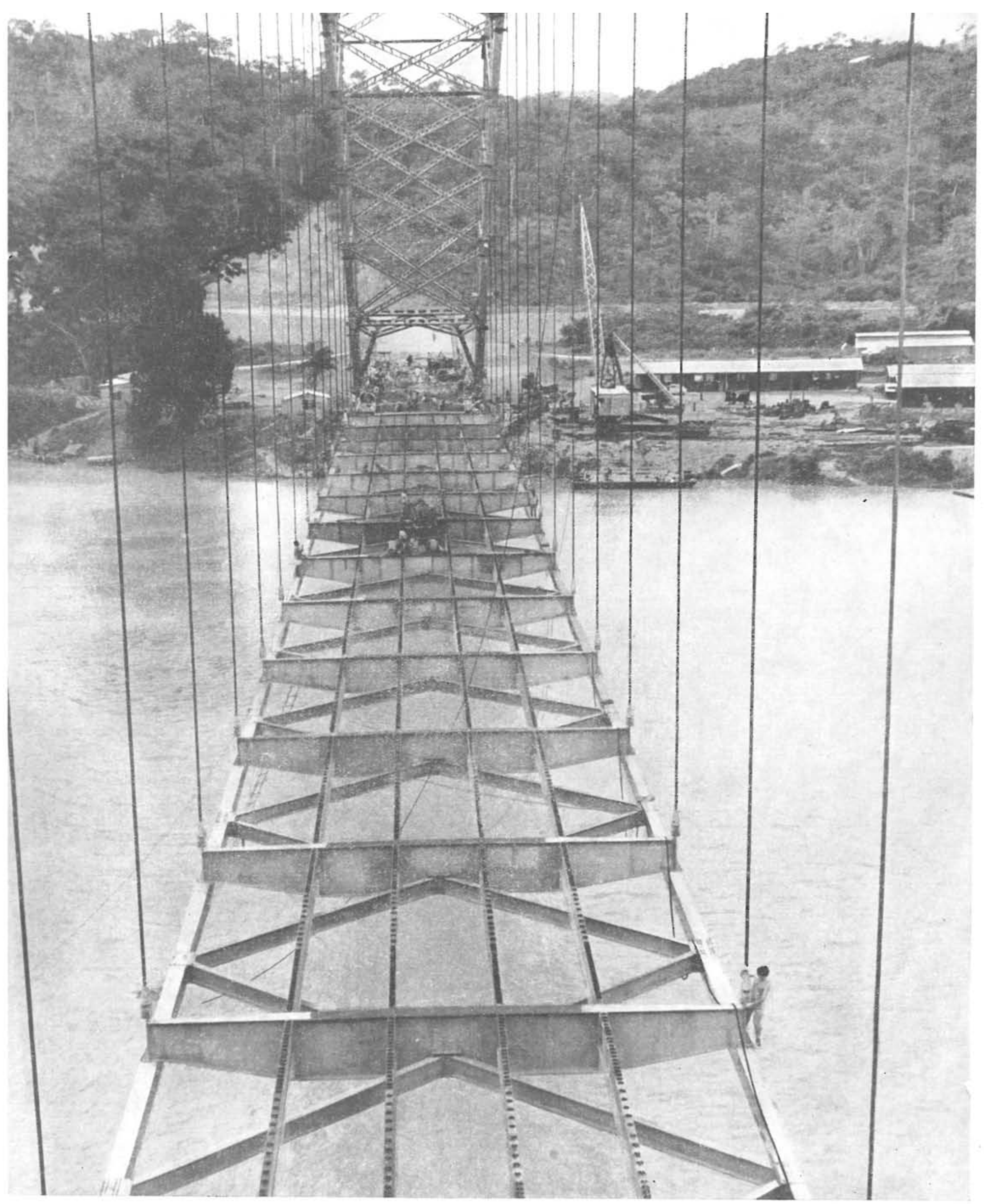

Entramado resistente del tablero. 
Salvada esta particularidad, se hormigonaron los bloques en dos fases: se rellenó el cuerpo de hormigón en masa, dejando un banco en el que se colocaron las placas de las dos articulaciones correspondientes a cada bloque; y, después, se hormigonó esta segunda parte armando el hormigón ligeramente en las proximidades de las patas de anclaje de las placas de las articulaciones.

Para las operaciones de montaje del puente en obra se había previsto utilizar todo el material del puente con carácter de permanente como material auxiliar de montaje, es decir, que los contratistas debían emplear el propio material del puente como ayuda para construir los entramados auxiliares de montaje.

El arco se montó en voladizo y en tres fases sucesivas:

En la primera fase, montada partiendo de grúas instaladas sobre pontones que se acercaban por el río, se procedió a montar la parte de entramado permanente del arco que permitiría la instalación de una grúa auxiliar de montaje sobre el extradós del primer trozo montado, grúa que después serviría para continuar el montaje hasta la clave o cierre.

En la segunda fase, la grúa auxiliar sirvió, sin otra ayuda, para montar este trozo; se reforzaron los vientos, y este material se utilizaría después como péndolas para la suspensión del tablero, añadiéndole más vientos.

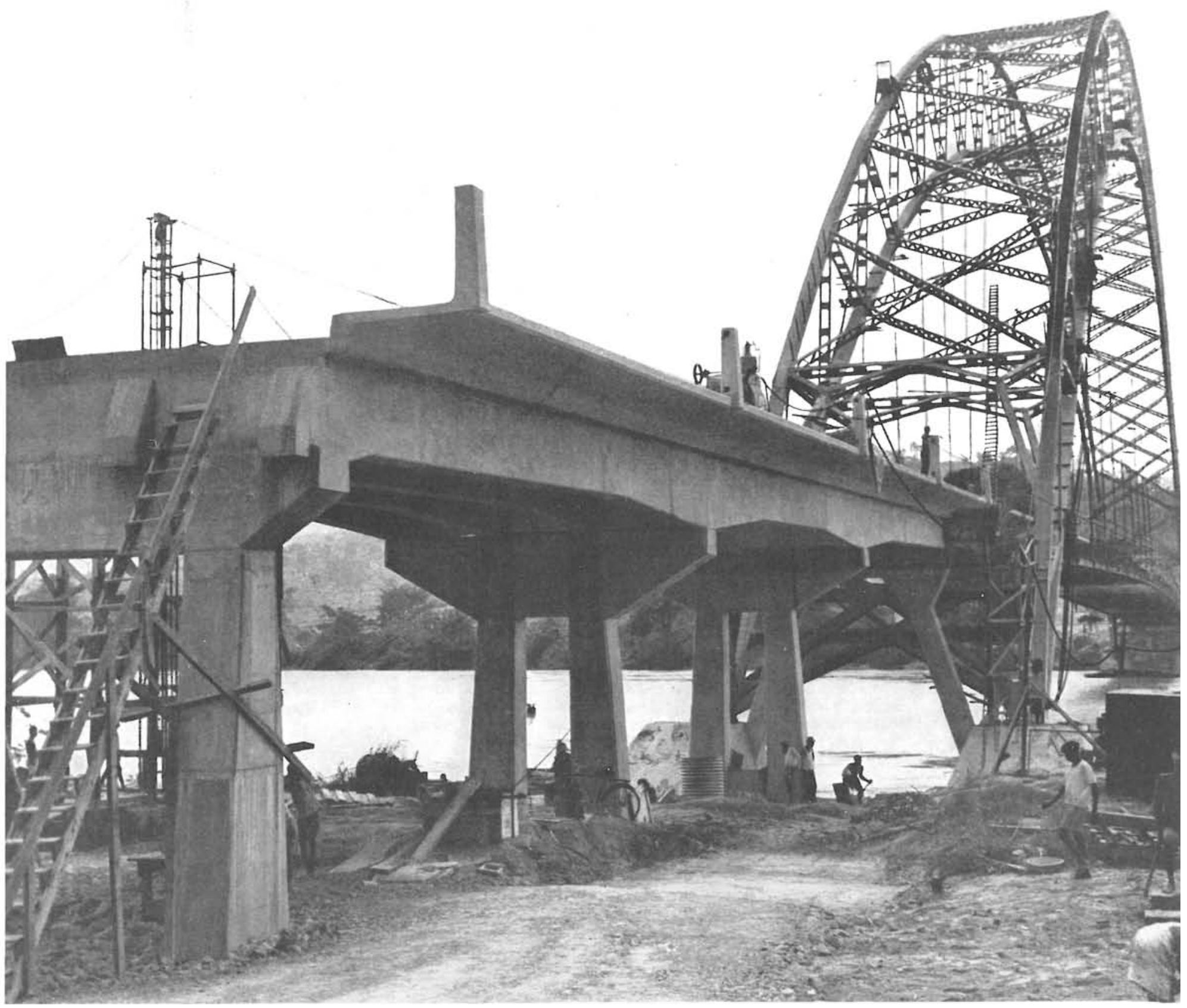




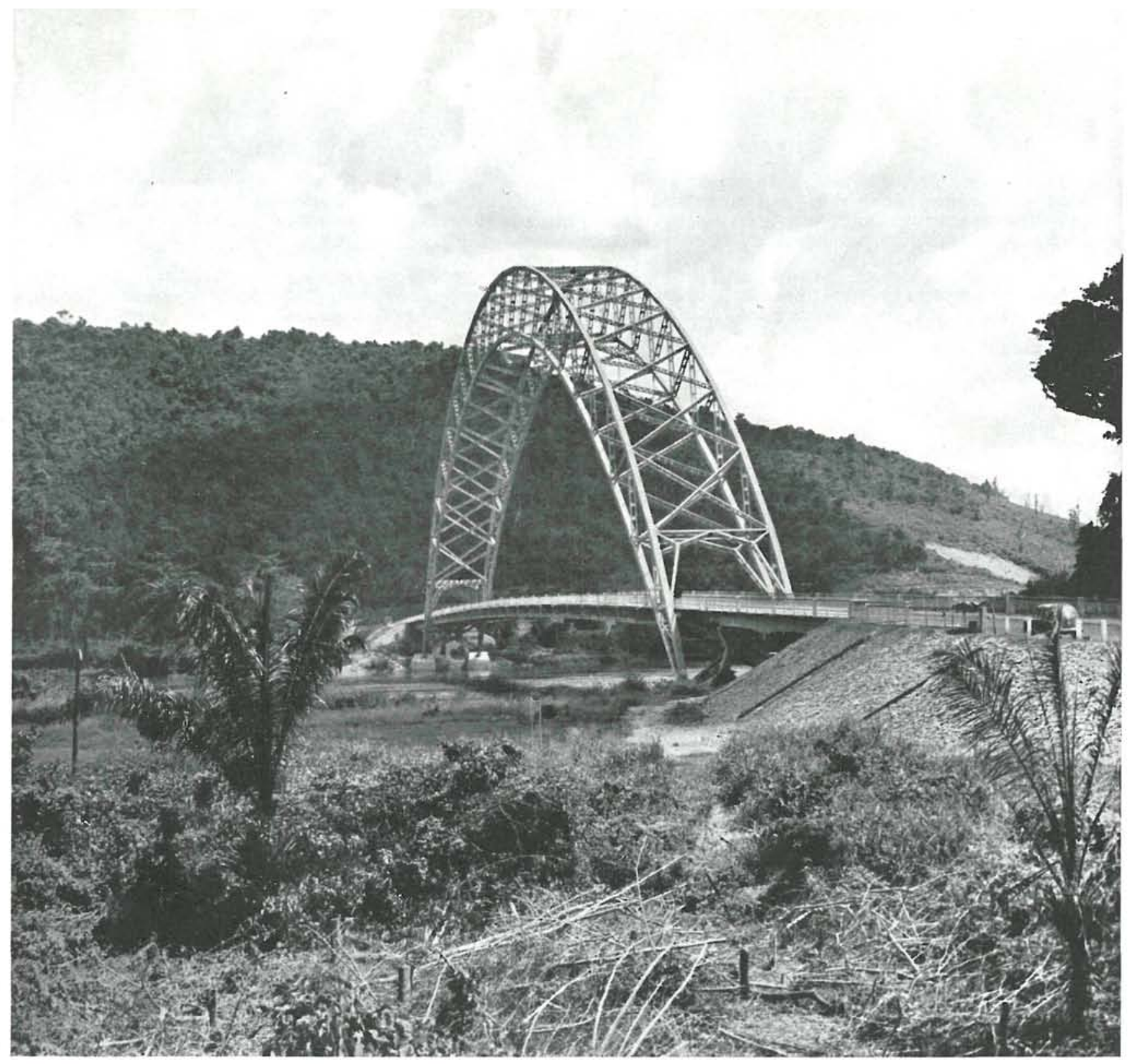

En la tercera y última fase se montó un mástil auxiliar en la parte inferior o zona del estribo, para dar mayor altura y dirección conveniente a los vientos que retenían el trozo montado en voladizo. Una vez terminadas estas operaciones se descendieron, con gran cuidado y precauciones, los dos semiarcos terminados, hasta lograr cerrar la estructura en la clave; esta operación se llevó a cabo con feliz éxito.

En las tres fases se había preparado un anclaje especial para los vientos que debían mantener suspendida la parte de arco que iba progresando a medida que avanzaba el montaje.

Cerrado el arco en su clave, la estructura se hallaba en un estado de equilibrio francamente vulnerable, respecto a la dirección transversal del viento, en el período de tiempo que debía transcurrir hasta la construcción del tablero. Para pasar a esta eventualidad se pensó en varias soluciones: lastre, arriostramiento con cables o vientos, y estructuras provisionales de rigidez que permitirian montar y hormigonar algunas zonas del tablero antes de haber terminado todo el entramado del mismo.

Para la mejor conservación de la estructura contra la oxidación, y teniendo en cuenta los desperfectos que en ella se habían originado durante el transporte y manipulaciones, se insistió para protegerla con nuevas capas a base de cinc.

En la preparación del proyecto intervinieron Sir William Halcrow \& Partners como ingenieros asesores de la administración de Ghana, y Freeman, Fox \& Partners fueron los encargados de proyectar el arco.

J. J. U. 